leadership on this issue. The results of Safe Roads | Safe Kids provide support for achieving these goals through public-private partnerships.

\section{IN-DEPTH ON-THE-SPOT ROAD ACCIDENT INVESTIGATION IN FINLAND}

${ }^{1}$ Kalle Parkkari, ${ }^{2}$ Inkeri Parkkari, 'Niina Sihvola. 'Finnish Motor Insurers' Centre, Traffic Safety Committee of Insurance Companies (VALT), Helsinki; ${ }^{2}$ Finnish Transport Safety Agency Trafi, Helsinki

\subsection{6/injuryprev-2016-042156.83}

Background In Finland, all fatal road traffic accidents are investigated in-depth, on-the-spot by multidisciplinary Accident Investigation Teams (Act on the Investigation of Road and Crosscountry Traffic Accidents 24/2001). The Finnish Motor Insurers' Centre maintains the investigations. The purpose of the teams is to find out what happened in the accident, uncover risk factors that turned an ordinary driving situation into a serious accident and give safety recommendations for improving road safety. Investigation teams do not take a stand on guilt or insurance compensation.

Methods General goal of Finnish road accident investigation is to prevent accidents from happening again and reduce serious consequences by learning from accidents. Currently there are 20 independent teams across Finland. The basic team members are police, road and vehicle specialists, physician and a psychologist. Teams use a standardised investigation method called VALT Method 2003. Focus of the investigation is on pre-crash circumstances, but also the crash and post-crash stages are investigated.

Results Teams produce safety recommendations which are connected to the risk factors. According to the investigation method teams look for both immediate and background risk factors which have contributed to the accident. Risk factors and safety recommendations are sought from the road user, vehicle, environment and the traffic system. Teams produce an investigation report on each case.

Compiled investigation folders of each case contain investigation forms from each member, pre-investigation protocol, forensic documents (autopsy and toxicology), photographs, sketches etc. The collected information form an accident database.

Conclusions The findings are used for making safety proposals and initiatives, and the information is used in statements, working groups and other cooperation efforts. The data is used for safety work of the authorities, safety research, education and public awareness campaigns.

\section{Safety Culture}

\section{Parallel Mon 1.4}

\section{OCCUPATIONAL SAFETY AND HEALTH AND WELL-BEING IN FUTURE WORK AND WORKING LIFE}

Päivi Mattila-Wiro, Päivi Hämäläinen. Ministry of Social Affairs and Health, Department for Occupational Safety and Health, Finland

\subsection{6/injuryprev-2016-042156.84}

Background Work and working life are changing rapidly. The changes affect also occupational safety and health and well-being at work. The occupational safety and health administration should be aware and present actions which have to be taken by today in order to be able to meet the future challenges in time. The aim is to avoid undesired development, change the anticipated development or to achieve a course of development that is better than expected.

Description of the problem Several reviews considering changes in future's working life have been published in Finland and elsewhere in the world. They have not, however, described changes from the perspective of occupational safety and health and wellbeing at work, nor proposed any actions to be taken by the occupational safety and health administration. The Working Life 2025 review which the occupational safety and health administration drew up responds to this need.

Results The future review looks at working life comprehensively starting from the question what kind of work will be done and who will be the future employees and ends up considering the employees' health and safety at work, well-being at work and the effects of new technologies on work.

Conclusions The technological development is more and more quickly, the risks of occupational safety and health are changing and they grow ever more complex as well as totally new risks will arise. The working life in future needs widely recognised perspective and flexibility. The diversification and the polarisation of the working life require a change also of the occupational safety and health administration.

\section{THE NEW CAMPAIGN OF THE GERMAN SOCIAL ACCIDENT INSURANCE ON "PREVENTION CULTURE"}

Gregor Doepke. Director of Corporate Communications and Chief Press Officer DGUV

\subsection{6/injuryprev-2016-042156.85}

Statistics show that there has been a significant decline in the number of occupational and commuting accidents over the last 100 years. Nevertheless, they also show that decline to have slowed over the last few years when compared with the twentieth century. Hence, the approaches taken to prevention to date may not be sufficient for the achievement of effective further progress towards the goal of Vision Zero- a world without serious or fatal accidents either in or on the way to and from the workplace or school.

It is now almost twenty years since the term "culture of prevention" was first used within the context of occupational safety and health in Germany. It heralded a newly developed appreciation for the fact that safety awareness among managers and employees alike is of key importance to the success of workplace prevention activities. The DGUV and its members tackle the topic of "prevention culture" in their new campaign.

They are the only organisation with responsibility for prevention and insurance cover all the way from preschool childcare, school, further education and working life right through to nursing care. This puts them in a position to credibly communicate and emphasise the message of prevention culture throughout all phases of human life. This message is: "Safety and health are values for every individual, organisation and society as a whole. They are to become an integral part of all actions. Preventative action is worthwhile and meaningful."

Therefore, the goal of the campaign is to highlight safety and health as values for every individual, organisation and society as a whole as well as to integrate them into societal mindset and action. In order to reach this goal, the campaign encompasses six fields of action: "Leadership", "Communication", 